\title{
Radiologic Assessment of Forward Head Posture and Its Relation to Myofascial Pain Syndrome
}

\author{
An Sun, MD ${ }^{1}$, Han Gyeol Yeo, MD' ${ }^{1}$ Tae Uk Kim, MD' ${ }^{1}$ Jung Keun Hyun, MD ${ }^{1,2,3}$, Jung Yoon Kim, MD $^{1}$ \\ ${ }^{1}$ Department of Rehabilitation Medicine, Dankook University College of Medicine, Cheonan; \\ ${ }^{2}$ Department of Nanobiomedical Science \& WCU Research Center, Dankook University, Cheonan; \\ ${ }^{3}$ Institute of Tissue Regeneration Engineering, Dankook University, Cheonan, Korea
}

\begin{abstract}
Objective To assess head posture using cervical spine X-rays to find out whether forward head posture is related to myofascial pain syndrome (MPS) in neck and shoulder.

Methods Eighty-eight participants who were diagnosed with MPS in neck and shoulder were evaluated in this study. Four parameters (distance among head, cervical spines, and shoulder, and cervical angle) were measured from lateral view of cervical spine X-ray. The location and number of trigger points in the neck and shoulder and symptom duration were evaluated for each patient.

Results Both horizontal distances between $\mathrm{C} 1$ vertebral body and $\mathrm{C} 7$ spinous process and between the earhole and $\mathrm{C} 7$ vertebral body were negatively correlated with cervical angle reflecting cervical lordosis $(\mathrm{p}<0.05)$. Younger patients had significantly $(\mathrm{p}<0.05)$ less cervical angle with more forward head posture. There was no relationship between MPS (presence, location, and number of trigger points) and radiologic assessments (distance parameters and the cervical angle).

Conclusion Forward head posture and reduced cervical lordosis were seen more in younger patients with spontaneous neck pain. However, these abnormalities did not correlate with the location or the number of MPS. Further studies are needed to delineate the mechanism of neck pain in patients with forward head posture.
\end{abstract}

Keywords Cervical vertebrae, Lordosis, Neck pain, Myofascial pain syndromes, Trigger points

Received June 16, 2014; Accepted August 11, 2014

Corresponding author: Jung Yoon Kim

Department of Rehabilitation Medicine, Dankook University College of Medicine, 119 Dandae-ro, Dongnam-gu, Cheonan 330-997, Korea

Tel: +82-41-550-6640, Fax: +82-41-551-7062, E-mail: schola21@gmail. com

(c) This is an open-access article distributed under the terms of the Creative Commons Attribution Non-Commercial License (http://creativecommons. org/licenses/by-nc/3.0) which permits unrestricted noncommercial use, distribution, and reproduction in any medium, provided the original work is properly cited.

Copyright $\odot 2014$ by Korean Academy of Rehabilitation Medicine

\section{INTRODUCTION}

As Internet network expands, weekly mean time a person spends at a computer has dramatically increased because many people have computers [1]. However, excessive computer use frequently results in musculoskeletal disorder on neck and shoulder [2,3]. The posture of staring at a monitor, located below the height of eyesight, makes the head move forward. Anterior curve in the lower cervical and posterior curve in the upper thoracic vertebrae could be exaggerated $[4,5]$. This is known as forward head posture or turtle neck syndrome [6-8]. 
A number of people with forward head posture complain of neck problems [9-11]. Previous studies reported that abnormal working posture with computer was associated with neck and shoulder pain due to musculoskeletal disorders, especially myofascial pain syndromes (MPS) [12,13]. Prolonged abnormal postures have been regarded as one of the causes of MPS. Therefore, treatment guideline for MPS includes re-education on desirable posture $[8,14]$. However, few studies have directly evaluated the relationship between forward head posture and MPS in neck and shoulder. The aims of this study were 1) to assess the head posture correctly using cervical spine X-rays and 2) to find out whether abnormal head posture is related to MPS in neck and shoulder.

\section{MATERIALS AND METHODS}

\section{Subjects}

The study was conducted from January 2006 to March 2009 at the Department of Rehabilitation Medicine, Dankook University Hospital in Korea. Data from patients

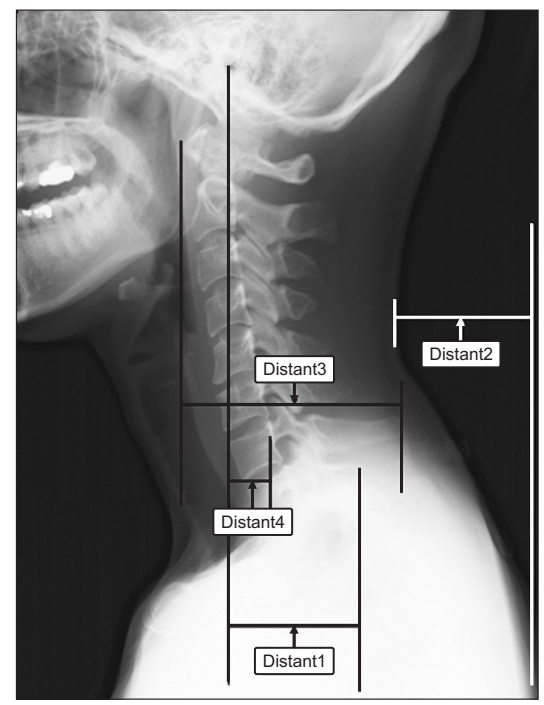

Fig. 1. The horizontal distance 1, 2, 3, and 4 were measured by using the lateral view of cervical spine X-ray. Distant 1 was the horizontal distance between the earhole and lateral shoulder. Distant 2 was the horizontal distance between plump line of posterior neck and posterior shoulder. Distant 3 was the horizontal distance between the anterior margin of $\mathrm{Cl}$ body and the posterior margin of $\mathrm{C} 7$ spinous process. Distant 4 was the horizontal distance between the earhole and midline of $\mathrm{C} 7$ lower margin. with posterior neck pain as their main complaints who were diagnosed with MPS were retrospectively extracted from their medical records. MPS was defined as regional muscle tenderness originated from myofascial trigger points [15]. Participants were excluded if they had any of the following conditions: 1) history of cervical trauma or surgery; 2) congenital anomalies involving the spine (cervical, thoracic, and lumbar); 3) bony abnormalities in spine; 4) any disorder of the central or peripheral nervous system; and 5) any systemic arthritis. Age, sex, and symptom duration were recorded. The study protocol was approved by the Institutional Review Board of the Dankook University Hospital (IRB No. DKUH-2014-05-016).

\section{Methods}

\section{Radiologic assessments}

Simple cervical spine X-rays were performed for the study subjects. To take a lateral view of the cervical spine, subjects were sitting in neutral position with head straight. Subjects were asked to elevate their chins straightly and to drop their shoulders as far as possible. The following five parameters were measured in the lateral view of cervical spine X-rays: distant 1 (D1), the horizontal distance between the earhole and lateral shoulder;

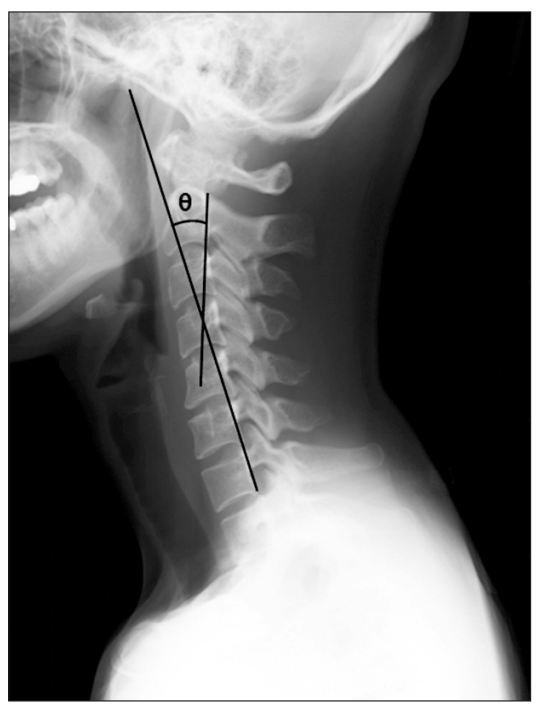

Fig. 2. The cervical angle was measured by using lateral view of cervical spine $\mathrm{X}$-ray. The angle from the $\mathrm{C} 2$ through $\mathrm{C} 7$ vertebrae using the posterior tangent method for analysis of cervical lordosis was depicted. The angle between the two tangent lines (C2-C7) at the posterior vertebral margins represented the curvature of the cervical spine [16]. 
distant 2 (D2), the horizontal distance between plump line of posterior neck and posterior shoulder; distant 3 (D3), the horizontal distance between the anterior margin of $\mathrm{Cl}$ body and the posterior margin of $\mathrm{C} 7$ spinous process; distant 4 (D4), the horizontal distance between the earhole and midline of C7 lower margin (Fig. 1); and cervical angle (CA) which was measured on lateral view of cervical spine $\mathrm{X}$-ray from the two tangent lines drawn on the posterior vertebral body margins of $\mathrm{C} 2-\mathrm{C} 7$ (posterior tangent method) [16] (Fig. 2).

\section{Clinical assessments}

The presence, location, and number of trigger points in neck and shoulder areas were evaluated for each patient. Scalenus, cervical paraspinal muscle, upper trapezius, levator scapulae, infraspinatus, supraspinatus, rhomboid, teres minor, deltoid, and sternocleidomastoid muscles were examined for myofascial trigger point. The following trigger points were diagnosed using the diagnostic criteria described by Travell and Simons [15]: 1) palpable taut band; 2) spot tenderness in taut band; 3) pain complaint by pressure on the tender nodule; 4) painful limit to full stretch range of motion; 5) visual or tactile local twitch response; and 6) local twitch response induced by needle penetration of tender nodule. Findings from (1) to (4) are essential to the diagnosis. Diagnosis is more certain when criterion (5) or (6) is present.

\section{Statistical analysis}

Spearman correlation coefficient was used to investigate the correlation between age, symptom duration, and five parameters. The association between MPS and five parameters were also subjected to Spearman correlation coefficient analysis. All statistical analyses were performed using SPSS ver. 12.0 (SPSS Inc., Chicago, IL, USA). Statistical significance was considered when p-values were less than 0.05 .

\section{RESULTS}

Two hundred and forty-eight persons who visited outpatient clinic with posterior neck pain from January 2006 to March 2009 were screened. Of them, 160 were excluded for the following reasons: history of cervical trauma or surgery $(n=45)$; congenital anomalies involving the spine $(n=2)$; bony abnormalities in spine $(n=11)$; disorder on nervous system diagnosed on electromyography ( $\mathrm{n}=93$ ); and systemic arthritis $(\mathrm{n}=9)$. A total of 88 participants (40 men and 48 women) were included in the study. The mean age was $41.4 \pm 12.4$ years. Symptom duration was $484.9 \pm 845.8$ days. The demographic data of patients are shown in Table 1.

Spearman correlation coefficients among age, symptom duration, CA, D1, D2, D3, and D4 are summarized in Table 2. D3 (the horizontal distances between $\mathrm{Cl}$ vertebral body and $\mathrm{C} 7$ spinous process) and the $\mathrm{D} 4$ (the horizontal distances between the earhole and $\mathrm{C} 7$ vertebral body) were negatively correlated with CA, reflecting cervical lordosis ( $\mathrm{r}=-0.257, \mathrm{p}=0.016$ and $\mathrm{r}=-0.374, \mathrm{p}<0.001$, respectively). All distance parameters had positive correlation with each other. Age was positively correlated with CA $(\mathrm{r}=0.376, \mathrm{p}<0.001)$ but negatively correlated with $\mathrm{D} 4(\mathrm{r}=-0.357, \mathrm{p}=0.001)$. However, the symptom duration did not show significant correlation with any other parameter (Table 2). There were no significant association between the five parameters and the symptom duration of MPS (Table 3). In addition, the numbers of trigger points did not show correlation with the five parameters. The most common location of trigger points was the upper trapezius muscle. The second most common location was the cervical paraspinal muscles. However, there was no relationship between the location of myofascial trigger points and the five parameters.

Table 1. Demographic characteristics of patients used in this study

\begin{tabular}{|lc|}
\hline \multicolumn{1}{|c|}{ Characteristic } & Value \\
\hline No. of subjects & 88 \\
\hline Age (yr) & $41.4 \pm 12.4$ \\
\hline Gender (male:female) & $40: 48$ \\
\hline Symptom duration (day) & $484.9 \pm 845.8$ \\
\hline Cervical angle $\left({ }^{\circ}\right)$ & $12.9 \pm 12.2$ \\
\hline Distance $1(\mathrm{~mm})$ & $51.9 \pm 15.6$ \\
\hline Distance $2(\mathrm{~mm})$ & $53.8 \pm 12.8$ \\
\hline Distance $3(\mathrm{~mm})$ & $86.5 \pm 13.9$ \\
\hline Distance $4(\mathrm{~mm})$ & $11.3 \pm 16.1$ \\
\hline
\end{tabular}

Values are presented as number or mean \pm standard deviation. 
Table 2. Spearman correlation coefficient (r) among age, duration of symptom, and the five parameters

\begin{tabular}{|c|c|c|c|c|c|c|c|}
\hline & Age & $\begin{array}{c}\text { Symptom } \\
\text { duration }\end{array}$ & $\begin{array}{c}\text { Cervical } \\
\text { angle }\end{array}$ & Distance 1 & Distance 2 & Distance 3 & Distance 4 \\
\hline Age & $\begin{array}{c}1.000 \\
-\end{array}$ & $\begin{array}{c}0.062 \\
(p=0.568)\end{array}$ & $\begin{array}{r}0.376^{* * *} \\
(\mathrm{p}<0.001)\end{array}$ & $\begin{array}{c}0.014 \\
(\mathrm{p}=0.895)\end{array}$ & $\begin{array}{c}0.061 \\
(\mathrm{p}=0.571)\end{array}$ & $\begin{array}{c}-0.019 \\
(\mathrm{p}=0.860)\end{array}$ & $\begin{array}{c}-0.357^{* *} \\
(\mathrm{p}=0.001)\end{array}$ \\
\hline Symptom duration & - & $\begin{array}{c}1.000 \\
-\end{array}$ & $\begin{array}{c}0.142 \\
(p=0.188)\end{array}$ & $\begin{array}{c}0.055 \\
(\mathrm{p}=0.616)\end{array}$ & $\begin{array}{c}0.009 \\
(p=0.933)\end{array}$ & $\begin{array}{c}0.000 \\
(p=0.997)\end{array}$ & $\begin{array}{c}0.102 \\
(p=0.346)\end{array}$ \\
\hline Cervical angle & - & - & $\begin{array}{c}1.000 \\
-\end{array}$ & $\begin{array}{c}0.022 \\
(p=0.839)\end{array}$ & $\begin{array}{c}-0.045 \\
(\mathrm{p}=0.678)\end{array}$ & $\begin{array}{c}-0.257^{*} \\
(\mathrm{p}=0.016)\end{array}$ & $\begin{array}{c}-0.374^{* *} \\
(\mathrm{p}<0.001)\end{array}$ \\
\hline Distance 1 & - & - & - & $\begin{array}{l}1.000 \\
-\end{array}$ & $\begin{array}{r}0.332^{* *} \\
(\mathrm{p}=0.002)\end{array}$ & $\begin{array}{r}0.292^{* *} \\
(\mathrm{p}=0.007)\end{array}$ & $\begin{array}{r}0.393^{* *} \\
(\mathrm{p}<0.001)\end{array}$ \\
\hline Distance 2 & - & - & - & - & $\begin{array}{l}1.000 \\
-\end{array}$ & $\begin{array}{r}0.376^{* *} \\
(p<0.001)\end{array}$ & $\begin{array}{c}0.234^{*} \\
(p=0.028)\end{array}$ \\
\hline Distance 3 & - & - & - & - & - & $\begin{array}{c}1.000 \\
-\end{array}$ & $\begin{array}{r}0.698^{* *} \\
(\mathrm{p}<0.001)\end{array}$ \\
\hline Distance 4 & - & - & - & - & - & - & $\begin{array}{c}1.000 \\
-\end{array}$ \\
\hline
\end{tabular}

${ }^{*} \mathrm{p}<0.05,{ }^{* *} \mathrm{p}<0.01$

Table 3. Correlation between myofascial pain syndrome and the five parameters

\begin{tabular}{lll}
\hline \multicolumn{1}{c}{ Variable } & r & p-value \\
\hline Symptom duration & & \\
Cervical angle & 0.142 & 0.188 \\
\hline Distance 1 & 0.055 & 0.616 \\
Distance 2 & 0.009 & 0.933 \\
\hline Distance 3 & 0.000 & 0.997 \\
\hline Distance 4 & 0.102 & 0.346 \\
Numbers of trigger points & & \\
Cervical angle & 0.053 & 0.627 \\
\hline Distance 1 & -0.094 & 0.393 \\
Distance 2 & -0.027 & 0.803 \\
\hline Distance 3 & -0.010 & 0.928 \\
Distance 4 & -0.023 & 0.832 \\
\hline
\end{tabular}

${ }^{*} \mathrm{p}<0.05$, significantly different according to Spearman correlation.

\section{DISCUSSION}

To our knowledge, this study was the first trial to analyze the relationship between forward head posture and MPS. Our results revealed that the greater the forward head position was, the more reduced the cervical lordosis was. This is consistent with a previous report [9]. In addition, according to linear regression analysis, younger patients showed more reduced CA and greater forward head position. In healthy individuals, the degree of forward head posture tends to be increased with age. The trend of this is associated with reduced range of motion in the cervical region $[17,18]$. However, after comparing the cervical angle of neck pain patients with age-matched pain-free subjects, one study explained that patients who complained spontaneous neck pain may have poorer posture than healthy individuals [11]. Older neck pain patients who have decreased cervical spine mobility due to age-related degenerative change seem to be little affected by poor posture when compared to younger neck pain patients [11]. The results of our study are consistent with the previous study, suggesting that some age-related factors may reduce the changes of cervical spine alignment in posterior neck pain patients. Further studies are needed to clarify this.

There was no relationship between the forward head position and the presence, location, and number of trigger points, suggesting that the mechanism of pain related to the forward head position does not account for myofascial trigger points. Even though mentally challenging computer work is associated with neck pain and forward head posture, only upper trapezius muscle activation was increased. Psychosocial stress with identical cognitive demands may evoke an increase in arousal along with an increase in upper trapezius muscle activity which might consequently lead to neck disturbance [19].

One plausible biomechanical explanation is that the 
pain associated with forward head position could be originated from the cervical facet joints. There are two mechanism of facet joint pain: excessive compression of the facet joint articulation and the capsular ligament strain beyond the physiologic limit in the forward head posture which stretches anterior structures of the neck and reduces the length of posterior muscles $[11,20]$. Facet joint compression could damage synovial folds that contain nociceptive nerve endings immunoreactive for substance $\mathrm{P}$ and calcitonin gene-related peptide, which could potentially lead to facet pain $[21,22]$. Because facet joints planes are obliquely oriented, the forward head position might increase the compressive force between the facet articular cartilage of the inferior articular process and the adjacent facet of the superior articular process [23]. The presence of mechanoreceptive and nociceptive nerve endings in cervical facet capsules plays important role in proprioception and pain sensation in the cervical spine $[24,25]$. Excessive capsular ligaments strain could potentially injure these structures, therefore generating pain [20]. Capsular ligament strain begins during extension but peaks as the facets were returning from maximal extension back to neutral position $[20,26]$. In patients with forward head position, cervical spine can be considered similar to a protracted position in which the lower cervical vertebrae are flexed in a forward glide with the upper cervical vertebrae extended [1,2,27]. Long standing hyperextensive state of upper cervical vertebrae can cause strain to the upper cervical facet capsular ligament.

Another possible cause is cervical root compression due to decreased cervical foraminal area in the forward head posture. When the forward head posture was corrected especially for lower cervical spine, it would improve the nerve root function by increasing the foraminal volume and area at the foraminal isthmus, which consequently relieves clinical symptoms [10].

There are some limitations of this study. Firstly, during assessment of forward head posture, measurement of CA and distance were disturbed by some technical problems. Forward head posture might be also combined with abnormal posture of shoulder, making it hard to set the fiducial point. In addition, because patients tended to be tense while taking radiographs, it was hard to measure the resting posture. Secondly, there were several difficulties in detecting trigger point. Human neck is covered by numerous layers of cervical muscles in anterior, lateral, and posterior aspects. Consequently, it was hard to distinguish each muscle selectively by manual method. Furthermore, because various factors could influence pain in the forward head posture, it was hard to select the pure effect of abnormal posture on myofascial pain. However, the risks mentioned above would be minimal because a highly trained and specialized medical doctor carefully diagnosed MPS. The measurement of CA and distance were evaluated by one researcher in order to reduce inter-researcher variations.

In conclusion, this study is the first trial to analyze the relationship between forward head posture and MPS assessed by using X-ray measurement. Younger patients with posterior neck pain showed more reduced cervical lordosis with greater forward head position. Reduced cervical lordosis associated with aging was affected by decreased cervical mobility and other factors. However, these abnormalities were not related to the location or the number of trigger points. Further studies are needed to delineate the mechanism of neck pain in patients with forward head posture. Larger controlled studies are needed to confirm the association between head posture and MPS.

\section{CONFLICT OF INTEREST}

No potential conflict of interest relevant to this article was reported.

\section{REFERENCES}

1. Kang JH, Park RY, Lee SJ, Kim JY, Yoon SR, Jung KI. The effect of the forward head posture on postural balance in long time computer based worker. Ann Rehabil Med 2012;36:98-104.

2. Chiou WK, Chou WY, Chen BH. Notebook computer use with different monitor tilt angle: effects on posture, muscle activity and discomfort of neck pain users. Work 2012;41 Suppl 1:2591-5.

3. Treaster D, Marras WS, Burr D, Sheedy JE, Hart D. Myofascial trigger point development from visual and postural stressors during computer work. J Electromyogr Kinesiol 2006;16:115-24.

4. Cho WH, Lee WY, Choi HK. An investigation on the biomechanical effects of turtle neck syndrome th- 
rough EMG analysis. Proceedings of the Korean Society of Precision Engineering Conference; 2008 Nov. p. 195-6.

5. Yoo WG, Yi CH, Cho SH, Jeon HS, Cynn HS, Choi HS. Effects of the height of ball-backrest on head and shoulder posture and trunk muscle activity in VDT workers. Ind Health 2008;46:289-97.

6. Mostamand J, Lotfi H, Safi N. Evaluating the head posture of dentists with no neck pain. J Bodyw Mov Ther 2013;17:430-3.

7. Peolsson A, Marstein E, McNamara T, Nolan D, Sjaaberg E, Peolsson M, et al. Does posture of the cervical spine influence dorsal neck muscle activity when lifting? Man Ther 2014;19:32-6.

8. Yoo WG. Effect of the neck retraction taping (NRT) on forward head posture and the upper trapezius muscle during computer work. J Phys Ther Sci 2013;25:581-2.

9. Yip CH, Chiu TT, Poon AT. The relationship between head posture and severity and disability of patients with neck pain. Man Ther 2008;13:148-54.

10. Diab AA, Moustafa IM. The efficacy of forward head correction on nerve root function and pain in cervical spondylotic radiculopathy: a randomized trial. Clin Rehabil 2012;26:351-61.

11. Silva AG, Punt TD, Sharples P, Vilas-Boas JP, Johnson MI. Head posture and neck pain of chronic nontraumatic origin: a comparison between patients and pain-free persons. Arch Phys Med Rehabil 2009; 90:669-74

12. Kim DQ, Cho SH, Han TR, Kwon HJ, Ha M, Paik NJ. The Effect of VDT work on work-related musculoskeletal disorder. Korean J Occup Environ Med 1998;10:524-33.

13. Fernandez-de-Las-Penas C, Cuadrado ML, Pareja JA. Myofascial trigger points, neck mobility, and forward head posture in episodic tension-type headache. Headache 2007;47:662-72.

14. Gupta BD, Aggarwal S, Gupta B, Gupta M, Gupta N. Effect of deep cervical flexor training vs. conventional isometric training on forward head posture, pain, neck disability index in dentists suffering from chronic neck pain. J Clin Diagn Res 2013;7:2261-4.

15. Travell JG, Simons DG. Myofascial pain and dysfunction: the trigger point manual (Volume 1. The upper extremities). 1st ed. Philadelphia: Williams \& Wilkins;
1983. p. 18-9.

16. Harrison DE, Harrison DD, Cailliet R, Troyanovich SJ, Janik TJ, Holland B. Cobb method or Harrison posterior tangent method: which to choose for lateral cervical radiographic analysis. Spine (Phila Pa 1976) 2000;25:2072-8.

17. Hsiao LP, Cho CY. The effect of aging on muscle activation and postural control pattern for young and older computer users. Appl Ergon 2012;43:926-32.

18. Boyle JJ, Milne N, Singer KP. Influence of age on cervicothoracic spinal curvature: an ex vivo radiographic survey. Clin Biomech (Bristol, Avon) 2002;17:361-7.

19. Shahidi B, Haight A, Maluf K. Differential effects of mental concentration and acute psychosocial stress on cervical muscle activity and posture. J Electromyogr Kinesiol 2013;23:1082-9.

20. Pearson AM, Ivancic PC, Ito S, Panjabi MM. Facet joint kinematics and injury mechanisms during simulated whiplash. Spine (Phila Pa 1976) 2004;29:390-7.

21. Inami S, Shiga T, Tsujino A, Yabuki T, Okado N, Ochiai $\mathrm{N}$. Immunohistochemical demonstration of nerve fibers in the synovial fold of the human cervical facet joint. J Orthop Res 2001;19:593-6.

22. Lee KE, Winkelstein BA. Joint distraction magnitude is associated with different behavioral outcomes and substance P levels for cervical facet joint loading in the rat. J Pain 2009;10:436-45.

23. Porterfield JA, DeRosa C. Mechanical neck pain: perspectives in functional anatomy. 1st ed. Philadelphia: Saunders; 1995. p. 83-115.

24. Dong L, Smith JR, Winkelstein BA. Ketorolac reduces spinal astrocytic activation and PAR1 expression associated with attenuation of pain after facet joint injury. J Neurotrauma 2013;30:818-25.

25. Lee KE, Davis MB, Mejilla RM, Winkelstein BA. In vivo cervical facet capsule distraction: mechanical implications for whiplash and neck pain. Stapp Car Crash J 2004;48:373-95.

26. Kirpalani D, Mitra R. Cervical facet joint dysfunction: a review. Arch Phys Med Rehabil 2008;89:770-4.

27. Yoo WG, An DH. The relationship between the active cervical range of motion and changes in head and neck posture after continuous VDT work. Ind Health 2009;47:183-8. 